\title{
Dry Eye Etiology: Focus on Friction
}

\section{Ätiologie des trockenen Auges: Reibung im Fokus}

The "dry eye" continues to gain importance in everyday clinical practice. Not only is it often a challenge from a medical point of view of differential diagnosis, but also therapeutically, the way to success is neither short nor well predictable. The time required for these patients should not be underestimated as well as the often-enormous suffering that is sometimes in no relation to the anatomical or physiological findings. Therefore, the models for dry eye and its pathogenesis are so important, as they often offer the most important guidance in the search for appropriate diagnosis and therapy for the ophthalmologist, especially if there is a lack of measurable findings. Trust in these models carries an obligation. Being a field of great dynamics, subject to newer and deeper insights into the dynamics of events, a constant reassessment and transformation of each model is therefore a compulsory necessity. In comparison to the previous, more static models, we are currently on the threshold of new thinking, appreciating more the dynamics and the physiological variability of the ocular surface and its lubrication dynamics. Most recently, the Tear Film and Ocular Surface Society (TFOS) published in its Dry Eye Work Shop II (DEWS II) report of the current expert consensus on the definition and classification of dry eye as a disease characterized by a loss of homeostasis of the tear film [1]. The definition of tear film homeostasis remained vague, acknowledging the possibility of many different changes that can occur in the tear film and ocular surface. The current classification of dry eye distinguishes two underlying but often overlapping etiologies: aqueous deficient and evaporative tear film. The report concludes that Meibomian Gland Disease is considered the leading cause of dry eye in clinic and populationbased studies. The TFOS DEWS II tear film report states that it is purported that the tear film lipid layer is responsible for the resistance of healthy tears against evaporation [2]. On the other hand, King-Smith and colleagues suggested a lack of corre- spondence between dry eye and both the lipid layer thickness and thinning rate [3]. The thinning rate of the tear film was not affected by apparent thickening of the lipid layer with lipid emulsion-based eye drops, suggesting that lipid was a poor barrier to evaporation [4]. Therefore, the DEWS II report concluded that the thickness of the lipid layer may not affect the evaporation rate unless it is very thin or completely absent. The TFOS pathophysiology report points to the enormous water-binding capacity of gel-forming mucins, like MUC5AC, secreted by the goblet cells of the conjunctiva as well as their moistening effect and lubricative function at the ocular surface [5-7].

The concentration of mucin MUC5AC in tears of patients with dry eye may be significantly decreased $[8,9]$. Moreover, the observed difference in tear and cellular conjunctival MUC5AC mobility suggests the possibility of cleavage of the molecule to smaller components [10]. Mucin deficiency causes functional and structural changes of the ocular surface $[11,12]$. The viscosity of the fluid-forming film is a major factor in the maintenance of a stable and coherent tear film. Polymeric mucous glycoproteins of high molecular weight are the main constituent molecules of all mucous secretions, and are responsible for the principle biochemical and physiological properties of these secretions [13]. From dilute high molecular weight hyaluronan solutions, it is known that the reduction of the concentration from 0.2 to 0.1 percent is associated with a decrease in viscosity at rest (zero shear viscosity) by a factor of 10 [14]. The same effect is associated with the decrease of average molecular weight of hyaluronan molecules in aqueous solution [15]. The decrease in concentration, glycosylation, or molecular weight of MUC5AC is associated with a very significant loss in lubricating efficacy of the tear film and an increase of friction between the cellular structures of the ocular surface.
Membrane-bound mucins at the apical surface of corneal and conjunctival epithelial cells, in particular, MUC1, MUC4 and MUC16, contribute to the antiadhesive character of the ocular surface $[16,17]$. Danjo and colleagues reported a significant alteration in the mucin on conjunctival epithelia in dry eyes [18]. This is likely to be one of the reasons for decreased wettability of the ocular surface in dry eye patients. Dogru and colleagues reported that in patients with atopic keratoconjunctivitis, the level of secreted MUC5AC is significantly below that of controls, whereas, the level of membrane-bound mucines is above that of controls $[19,20]$. They conclude that persistence of inflammation and a decline of the expression of the major ocular surface mucin, MUC5AC, may stimulate the upregulation of other epithelial mucins to protect the ocular surface.

The decrease in either molecular weight, glycosylation, or concentration of MUC5AC in the tear film is, moreover, associated with a significant loss of the water binding capacity of glycosaminoglycanes, which constitute the side chains of mucins [21]. This might well be one of the main causes for evaporative dry eyes.

The elevated friction, reduced hydration, and increased evaporation rate of mucous-deficient tear film in combination with alterations in the membrane-bound mucins of the ocular surface are likely to be the main causes for lid wiper epitheliopathy, LIPCOF, and sandbank epitheliopathy [22-24].

Other clinical situations resulting in increased friction between lids and the ocular globe are anatomical irregularities of the ocular surface [25]. These may be caused by tissue-related changes, like in keratoconus, as a consequence of infection or burns, or, frequently, as a consequence of ocular surgery [26]. Unless controlled, increased friction may be a major cause of tissue scarring. 
None of these clinical situations has an aqueous deficient or evaporative tear film as the underlying etiology, but the elevated friction may be caused by a mucous deficient tear film, insufficient antiadhesive properties, or irregularities of the ocular surface. It is therefore proposed to recognize friction as an additional independent etiology for dry eye disease.

\section{Conflict of Interest}

The authors declare that they have no conflict of interest.

Authors

Gysbert Botho van Setten ${ }^{1,2}$, Wolfgang MuellerLierheim ${ }^{3}$, Christophe Baudouin ${ }^{4}$

1 Klin Neuroscience, Karolinska Institutet, St Eriks Eye Hospital, Stockholm, Sweden

2 Dept Ob/Gyn Dept of Ophthalmology, University of Florida, Gainesville, Florida, United States

3 CORONIS Foundation, Munich, Germany

4 Centre Hospitalier National d'Ophtalmologie des Quinze-Vingts, Universite Versailles SaintQuentin-en-Yvelines, Paris, France

\section{Correspondence}

PD Gysbert Botho van Setten,
MD, PhD, PhD
Karolinska Institutet
Klin Neuroscience
St Eriks Eye Hospital
Polhemsgatan 50
17177 Stockholm
Sweden
Phone: + 4686723298
Fax: +4686723070
gysbert-botho.vansetten@sll.se

\section{References}

[1] Craig JP, Nichols KK, Akpek EK et al. TFOS DEWS II Definition and Classification Report. Ocul Surf 2017; 15: 276-283. doi:10.1016/j. jtos.2017.05.008

[2] Willcox MDP, Argueso P, Georgiev GA et al. TFOS DEWS II Tear Film Report. Ocul Surf 2017; 15: 366-403. doi:10.1016/j.jtos.2017. 03.006
[3] King-Smith PE, Reuter KS, Braun RJ et al. Tear film breakup and structure studied by simultaneous video recording of fluorescence and tear film lipid layer images. Invest Ophthalmol Vis Sci 2013; 54: 4900-4909. doi:10.1167/iovs.13-11878

[4] King-Smith PE, Hinel EA, Nichols JJ. Application of a novel interferometric method to investigate the relation between lipid layer thickness and tear film thinning. Invest Ophthalmol Vis Sci 2010; 51: 2418-2423. doi:10.1167/iovs.09-4387

[5] Bron AJ, de Paiva CS, Chauhan SK et al. TFOS DEWS II pathophysiology report. Ocul Surf 2017; 15: 438-510. doi:10.1016/j.jtos.2017. 05.011

[6] Mantelli F, Argueso P. Functions of ocular surface mucins in health and disease. Curr Opin Allergy Clin Immunol 2008; 8: 477-483. doi:10.1097/ACl.0b013e32830e6b04

[7] Cher I. A new look at lubrication of the ocular surface: fluid mechanics behind the blinking eyelids. Ocul Surf 2008; 6: 79-86

[8] Ralph RA. Conjunctival goblet cell density in normal subjects and in dry eye syndromes. Invest Ophthalmol 1975; 14: 299-302

[9] Argueso P, Balaram M, Spurr-Michaud S et al. Decreased levels of the goblet cell mucin MUC5AC in tears of patients with Sjogren syndrome. Invest Ophthalmol Vis Sci 2002; 43: 1004-1011

[10] Spurr-Michaud S, Argueso P, Gipson I. Assay of mucins in human tear fluid. Exp Eye Res 2007; 84: 939-950. doi:10.1016/j.exer. 2007.01.018

[11] Floyd AM, Zhou X, Evans C et al. Mucin deficiency causes functional and structural changes of the ocular surface. PLoS One 2012; 7: e50704. doi:10.1371/journal.pone. 0050704

[12] Baudouin C, Rolando M, Benitez Del Castillo $\mathrm{JM}$ et al. Reconsidering the central role of mucins in dry eye and ocular surface disease. Prog Retin Eye Res 2018. doi:10.1016/j. preteyeres.2018.11.007

[13] Kaura R, Tiffany JM. The role of mucous glycoproteins in the tear film. In: Holly FJ, ed. The preocular tear film. Lubbock, TX: Dry Eye Institute; 1986: 728-732

[14] Bothner H, Waaler T. Rheological characterization of tear substitutes. Drug Dev Ind Pharm 1990; 16: 755-768

[15] Bothner H, Wik O. Rheology of hyaluronate. Acta Otolaryngol Suppl 1987; 442: 25-30

[16] Hilkens J, Ligtenberg MJ, Vos HL et al. Cell membrane-associated mucins and their adhesion-modulating property. Trends Biochem Sci 1992; 17: 359-363

[17] Sumiyoshi M, Ricciuto J, Tisdale A et al. Antiadhesive character of mucin O-glycans at the apical surface of corneal epithelial cells. Invest Ophthalmol Vis Sci 2008; 49: 197203. doi:10.1167/iovs.07-1038

[18] Danjo Y, Watanabe H, Tisdale AS et al. Alteration of mucin in human conjunctival epithelia in dry eye. Invest Ophthalmol Vis Sci 1998; 39: 2602-2609

[19] Dogru M, Okada N, Asano-Kato N et al. Alterations of the ocular surface epithelial mucins $1,2,4$ and the tear functions in patients with atopic keratoconjunctivitis. Clin Exp Allergy 2006; 36: 1556-1565. doi:10.1111/j.13652222.2006.02581.x

[20] Dogru M, Matsumoto Y, Okada N et al. Alterations of the ocular surface epithelial MUC16 and goblet cell MUC5AC in patients with atopic keratoconjunctivitis. Allergy 2008; 63: 1324-1334. doi:10.1111/j.1398-9995. 2008.01781.x

[21] Takigami S, Takigami M, Phillips GO. Hydration characteristics of the cross-linked hyaluronan derivative hylan. Carbohydr Polym 1993; 22: 153-160

[22] Korb DR, Herman JP, Blackie CA et al. Prevalence of lid wiper epitheliopathy in subjects with dry eye signs and symptoms. Cornea 2010; 29: 377-383. doi:10.1097/ICO. 0b013e3181ba0cb2

[23] Hoh H, Schirra F, Kienecker C et al. [Lid-parallel conjunctival folds are a sure diagnostic sign of dry eye]. Ophthalmologe 1995; 92: 802-808

[24] van Setten G. Sandbank Epitheliopathy of the Conjunctiva (SEC) A New Indicator in Dry Eye Diagnostics for Optimized Ocular Surgery. J Eye Cataract Surg 2017; 3: 1-4. doi:10.21767/2471-8300.100029

[25] van Setten G. The Anatomical Dry Eye A Different Form of Ocular Surface Disease Deserves Focus. Open J Ophthalmol 2017; 7: 184-190. doi:10.4236/ojoph.2017.73025

[26] van Setten G. Epitheliopathy of the bleb (EoB) - identifying attrition: A new model for failure of glaucoma surgery. New Front Ophthalmol 2018. doi:10.15761/NFO. 1000199

\section{Bibliography}

published online 30.7.2019

Klin Monatsbl Augenheilkd 2020; 237: 1235-1236

DOI 10.1055/a-0898-3857

ISSN 0023-2165

(C) 2020. Thieme. All rights reserved.

Georg Thieme Verlag KG, Rüdigerstraße 14,

70469 Stuttgart, Germany

\section{(ㄷ) (i) () $\odot$}

